\title{
Residential Load Curve Analysis during Electric Vehicle Charging
}

\author{
Fernanda Cristina Martins Cortezzi, Patrícia Romeiro da Silva Jota \\ Electrical Engineering Department, Federal Center of Technological Education of Minas Gerais_CEFET-MG, \\ Belo Horizonte, Brazil \\ Email: fernanda.cortezzi@gmail.com, prsjota@des.cefetmg.br
}

How to cite this paper: Cortezzi, F.C.M. and da Silva Jota, P.R. (2017) Residential Load Curve Analysis during Electric Vehicle Charging. Journal of Power and Energy Engineering, 5, 49-61.

https://doi.org/10.4236/jpee.2017.53004

Received: February 8, 2017

Accepted: March 27, 2017

Published: March 30, 2017

Copyright ( 92017 by authors and Scientific Research Publishing Inc. This work is licensed under the Creative Commons Attribution International License (CC BY 4.0).

http://creativecommons.org/licenses/by/4.0/

c) (i) Open Access

\begin{abstract}
With the objective to reduce the environmental pollution, alternative initiatives have favored the evolution of the electric vehicle (EV). As the electric vehicle depends solely on battery, the grid electric power is need for charging it. This new electric load can cause concern due to the impact of consume on power system. The behavior of main electric parameters is analyzed during the recharge of EV considering an actual condition of diary charge. In sequence, the data of these electric parameters obtained during EV charging were included on residential consumer energy from Brazil. The results contribute to the understanding of the recharge of EV in different time of the day which can affect the curve of residential consumer energy and consequently will affect in different way on Power System.
\end{abstract}

\section{Keywords}

Electric Vehicle, Electric Vehicle Charging, Power System,

Residential Consume

\section{Introduction}

In these days, it is impossible to think in urban mobility without considering the automobile, which has become an indispensable asset. The Electric Vehicle (EV) has represented significant parts of automobiles markets. Since Kyoto protocol, occurred in 1997, environmental initiatives have favored the evolution of the electric power train, with objective to reduce the environmental pollution [1]. Electric vehicle has no emission of pollutants into the atmosphere and also any noise. Due to these features, various governments are proposing strong policies, including legislations, benefits and rebates and consequently making reality the adoption of EV like way of urban mobility. Therefore, the less autonomy and the long time to recharge remain the EV great disadvantages. As this vehicle de- 
pends solely on battery, electric power is needed from the grid for charging [2]. The rapid growth of electric vehicle, associate with less autonomy, impacts definitely in increases of energy demand. The extra energy, demand of EV, can cause the distribution circuit congestion and affects the power quality [3]. However, before to think about the increase and quality of energy, it is necessary to investigate the impact on power system. The study reported in this paper presents the behavior of main electric parameters, like voltage (V), current (I), harmonic distortion (THD), active power $(\mathrm{P})$, reactive power $(\mathrm{Q})$, apparent power $(\mathrm{S})$ and power factor (FP) during the recharge of VE. Thus, after to know the behavior of electric parameters, it is possible to discuss the general effect on distribution systems caused by the spread of EV. In sequence, these electric parameters will be included on residential consumer energy of Brazil. The recharge of EV in different time of the day can affect the curve of residential consumer energy and consequently will affect in different way on Power System.

\section{Literature Review}

The researches associated with EV present different aspects, especially about solutions due the less autonomy and studies about the impact of consume on power system. Regarding the less autonomy of EV, the main researches include analyses of new technologies and tests of batteries and chargers. It was proposed by [4], a new configuration for a Hybrid Energy Storage System (HESS). Utilizing the combination with battery, ultra-capacitors and bi-directional DC/DC converter, it was possible to achieve a better overall performance as well as extend the battery life. Concerning chargers, it was studied a method to provide automatic positioning of the charging stations by service area division by [5]. They assume that the electric car owners are always looking for the nearest charging station and the premise of the popularity of EV is to solve the positioning of the charging stations. The need to increase the number of chargers is due the introduction of EVs in scale. As a consequence, it comes with an increase in electricity demand. According to [6], in most of the cases, the distribution grid transfers energy without any kind of control mechanism. In a study done by [3] it was proposed an Advanced Metering Infrastructure (AMI), where it is possible to introduce a charging schedule system to advice the charging mode to avoid the peak consumption. The objective is to reduce the peak consumption, to relocate the EV energy demand to "off peak" consumption and to reshape the load profile. One of the concerns about the issues regarding EVs penetration in power grid is about quality power of electric system [6]. In [2] it was found a research about how EV can affect the quality power of electric system. It was done measurements and analyses of harmonic propagation during EV charging, especially when a group of EVs is connected to the grid simultaneously for charging. The founded harmonic contamination values were lower than the limit set by utility and the EV charging on electrical grid is not as critical as thought by most of power system researches and engineers. It also proves that the THD for both voltage and current from a group of EVs are not found the di- 
rect summation of the THD from a single vehicle [2]. The impact of EV's consumption on power system is totally related with the less autonomy of the vehicle. The lower the efficiency, more power energy will be necessary and more time will be spent to recharge the EV. From the studies realized, this paper analyzes the impact caused by the recharge of EV on a residence in Brazil. This paper is organized as follows: First it is presented the materials and methods used to get the electric parameters data during EV charging. Then it is presented the electric parameters obtained data during EV charging. Finally, the behavior of the residential load curve and the impact of the EV charge in it is analyzed and discussed.

\section{Materials and Methods}

To analyze the EV autonomy in Brazilian cities, some reference data is used. As the average travelled distance by each vehicle in Brazilian cities is 15.000 $\mathrm{km} /$ year [7], consequently the travelled daily distance is approximately 41 $\mathrm{km} /$ day. The measurement was performed on a commercial type EV with Li-ion battery within $24 \mathrm{kWh}$ of energy. Due to sensitive issues, the name of the brand of this EV is not disclosed. The performance of this VE is $121 \mathrm{MPGe}$ (miles per gallon), which correspond $5.78 \mathrm{~km} / \mathrm{kWh}$ [8]. After travelled $41 \mathrm{~km}$, considering the discharge condition in $5.78 \mathrm{~km} / \mathrm{kWh}$, in the end of day the battery of EV will be with $70 \%$ of state of charge (SOC). According to [2], one of the concerns with electric vehicle charging is the harmonic contamination to the electric grid. Harmonic limits are recommended by nationals and internationals standards [9] [10] [11]. The IEEE 519-2014 and IEC 61000-3-2:2014 are the major internationals standards on harmonic emission that are widely used. In Brazil, the most important standard is the PRODIST Module 8. The IEEE 519 recommends limits for both voltage and current only at the point of common coupling (PCC) where others equipment are, or could be, connected. The PCC is a point located upstream of the considered installation and for bus voltage at PCC less than 1 $\mathrm{kV}$, the total harmonic voltage distortion (THDv) is $8 \%$. For users connected to systems where the rated voltage at the PCC is $120 \mathrm{~V}$ to $69 \mathrm{kV}$ the maximum total harmonic voltage distortion (THDi) is 5\% [9]. Even though that standard should not be applied to either individual pieces of equipment, the limits recommended will not be considered. The IEC 61000 sets limits of equipment whose input current is equal or less than $16 \mathrm{~A}$ and differs from the IEE 519 because it does not stipulate a limit on the harmonic current emission from the individual loads, irrespective of their characteristics or topology. The IEC 61000 classifies the loads in four classes A-D [10].

- Class A: Three phase equipment, fixed tools, audio equipment and other equipment that is not classified as class B, C or D;

- Class B: Portable tools, non-professional arc welding equipment;

- Class C: Lighting equipment;

- Class D: Equipment with power less than $600 \mathrm{~W}$ like personal computers, tablets, television receivers. 
The EV will be considered on class A due to it was not included in other classes. For class A the standard sets the harmonic current in the absolute limit of $2.3 \mathrm{~A}[10]$.

The main standard about quality power in Brazil is PRODIST Module 8 [11] where establishes limits for harmonic voltage distortion and power factor. For current there is no distortion limit set. The standard has set the limit on the percentage of total harmonic voltage distortion (THDv) of $10 \%$ and for power factor the limit is between 1 and 0.92 (inductive or capacitive) [11]. Figure 1 is the wiring schema used to measurement the electric parameters during EV charging. The measurement was performed using an energy analyzer which has the capability to display the measurements in real time and to save the measurement data into the memory [12]. Thus, the EV charging was realized on voltage level 220 $\mathrm{V} / 60 \mathrm{~Hz}$ between two phases, L1 and L2.

The measured electric parameters data during the EV charging are presented on Table 1. Using the meter it were possible to measure electric parameters at each phase (L1 or L2) and phase-to-phase (L1-L2) and the obtained results are presented on the next section.

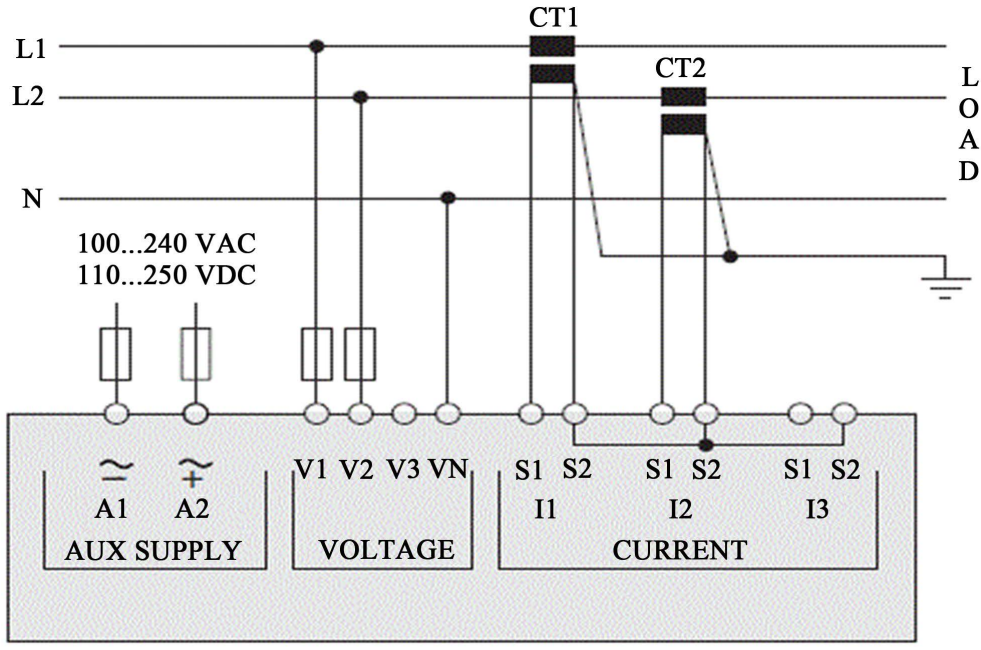

Figure 1. Digital multimeter measurement schema [12].

Table 1. Measured electric parameters data during the EV charging.

\begin{tabular}{ccc}
\hline Electric Parameters & Symbol & Unit \\
\hline Voltage & $\mathrm{V}$ & $\mathrm{V}$ \\
Current & $\mathrm{I}$ & $\mathrm{A}$ \\
Total Voltage Harmonic Distorcion & THDv & $\%$ \\
Total Current Harmonic Distorcion & THDi & $\%$ \\
Active Power & $\mathrm{P}$ & $\mathrm{W}$ \\
Reactive Power & $\mathrm{Q}$ & VAR \\
Apparent Power & $\mathrm{S}$ & VA \\
Power Factor & PF & Dimensionless \\
\hline
\end{tabular}




\section{Electric Parameters Behavior during EV Charging}

The EV charging was monitored by the meter since $70 \%$ SOC until $100 \%$ SOC of battery. Every time that the charge of battery increased in $10 \%$ of state of charge (SOC) a new measurement was done. This information was obtained through the state of charge present in vehicle cluster. The total time to recharge was 3 hours and 4 minutes. Table 2 shows the interval time to achieve each increase of $10 \%$, since $70 \%$ until $100 \%$ SOC.

Figure 2 shows the voltage and THDv measured phase-to-phase (L1-L2) during EV charging. During EV charging, the voltage has presented small variation and the maximum THDv found was $0.90 \%$. The voltage and THDv on phase L1 and L2 to ground are shown on Figure 3 and Figure 4, respectively. In both figures, the measured value of voltage also have presented small variation.

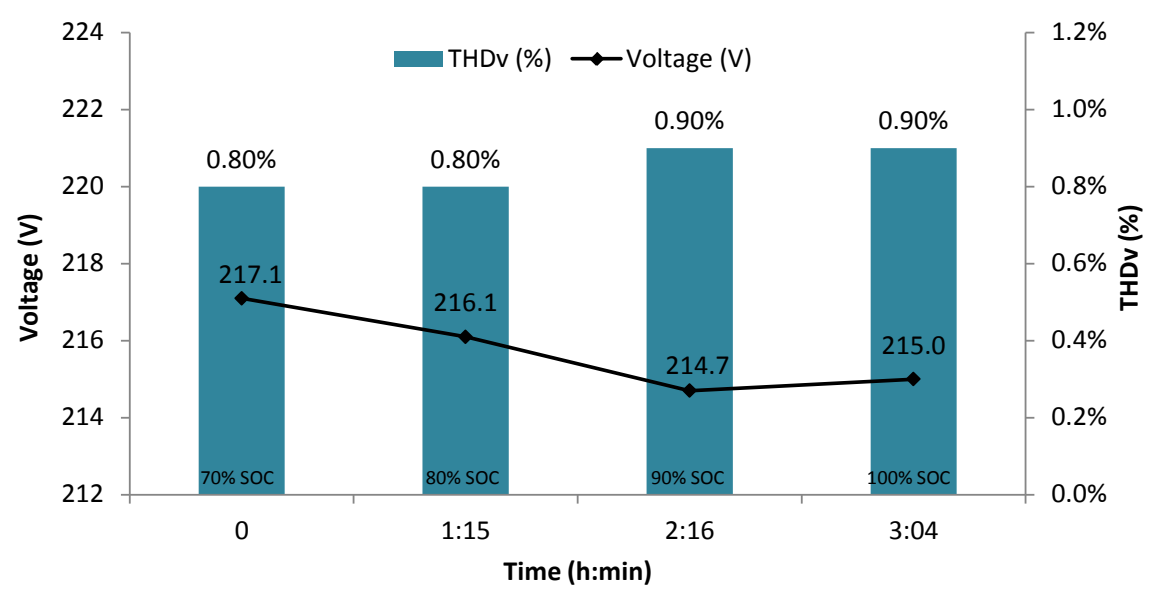

Figure 2. Voltage and THDv, phase-to-phase, during EV charging.

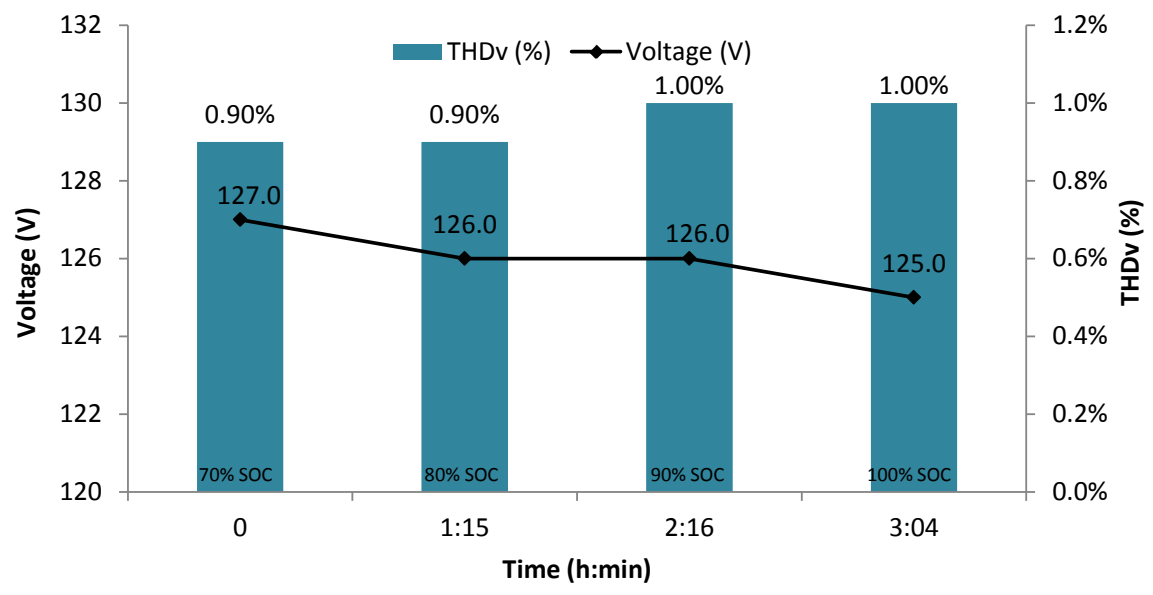

Figure 3. Voltage and THDv, on phase L1, during EV charging.

Table 2. Measurement interval of EV charging.

\begin{tabular}{ccccc}
\hline State of charge (\%SOC) & $70 \%$ & $80 \%$ & $90 \%$ & $100 \%$ \\
\hline Time (h:min) & 0 h 0 min & 01 h 15 min & 02 h 16 min & 03 h 04 min \\
\hline
\end{tabular}




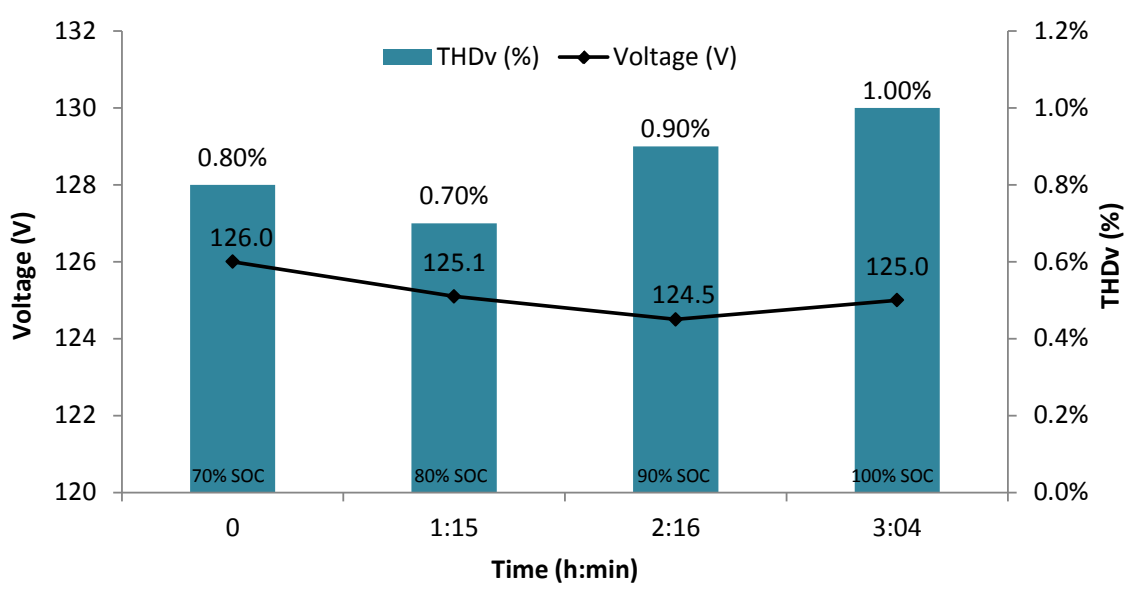

Figure 4. Voltage and THDv, on phase L2, during EV charging.

The higher measured value of THDv was $1 \%$. Therefore, all the presented results are low of the set limit of standard PRODIST Module 8 used by this paper [11].

Concerning the current analysis, the measured current and THDi, on phase L1 and L2 are shown on Figure 5 and Figure 6, respectively, since an analysis about the current is also very important. It can be seen that during EV charging, current and THDi presented low values, much smaller than the regular electronic loads. The maximum value found was $6.5 \%$ what represent $0.37 \mathrm{~A}$, a value lower than the set limit of standard IEC 61000 used by this paper [10].

The behavior of the active, reactive and apparent powers $(\mathrm{P}, \mathrm{Q}, \mathrm{S})$ and power factor during EV charging, phase-to-phase, can be observed in Figure 7. The same variables, but now in each phase (L1 and L2), can be observed separately in Figure 8 and Figure 9. Analysing Figure 7 it can be observed that the total active power of the EV is almost equal to the apparent power. This occurs because the reactive power has presented a low value causing a very high power factor. As a consequence the power factor stayed inside the standard limit of PRODIST Module 8 . However, when each phase is analysed separately it can be seen that the reactive power presents high values. As a consequence the power factor values stay out of set limit. In this case, one of the phases presents a capacitive reactive power and the other phase presents an inductive reactive power. As the reactive power compensation between the phases is obtained, the total reactive power achieves power quality standard.

\section{Electric Vehicle Recharge on Residential Consumer}

The adoption of EV like way of urban mobility impacts definitely in increases of electric energy demand. Due to the insufficient public charge infrastructure, the expectation is that $60 \%$ of EV is recharged at home [13]. When a EV is recharged at home, this charging behavior affects the residential consume and also the residential load curve. A research has been done about the income of EV owners and according to [14], $83 \%$ of the households have yearly income higher than $\$ 100$ Thousand Dollars and 46\% of households have incomes higher than $\$ 150$ Thousand Dollars. Most of the EV owners are included in middle and up- 


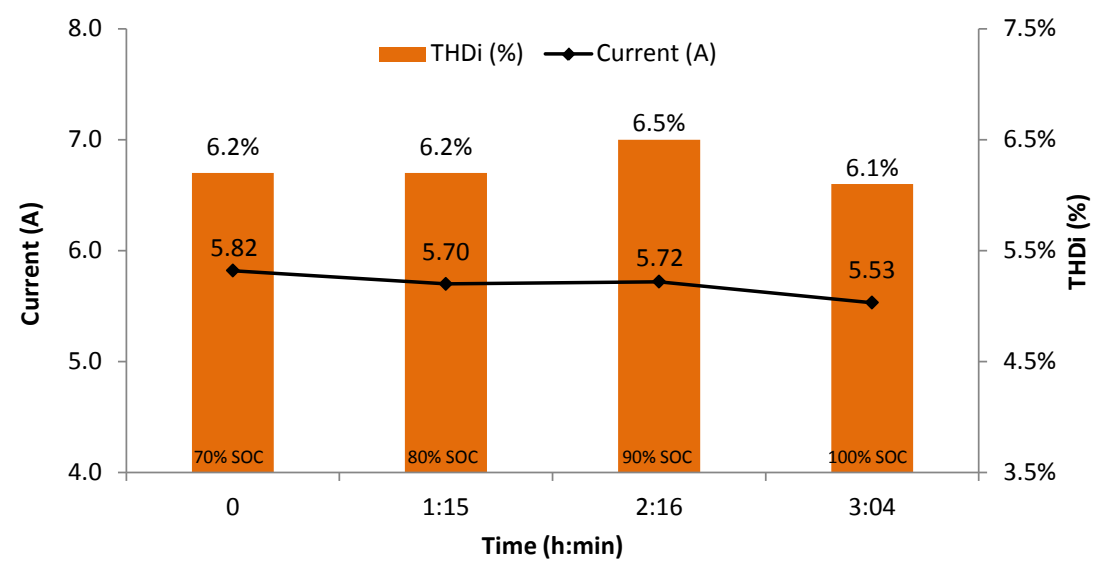

Figure 5. Current and THDi, on phase L1, during EV charging.

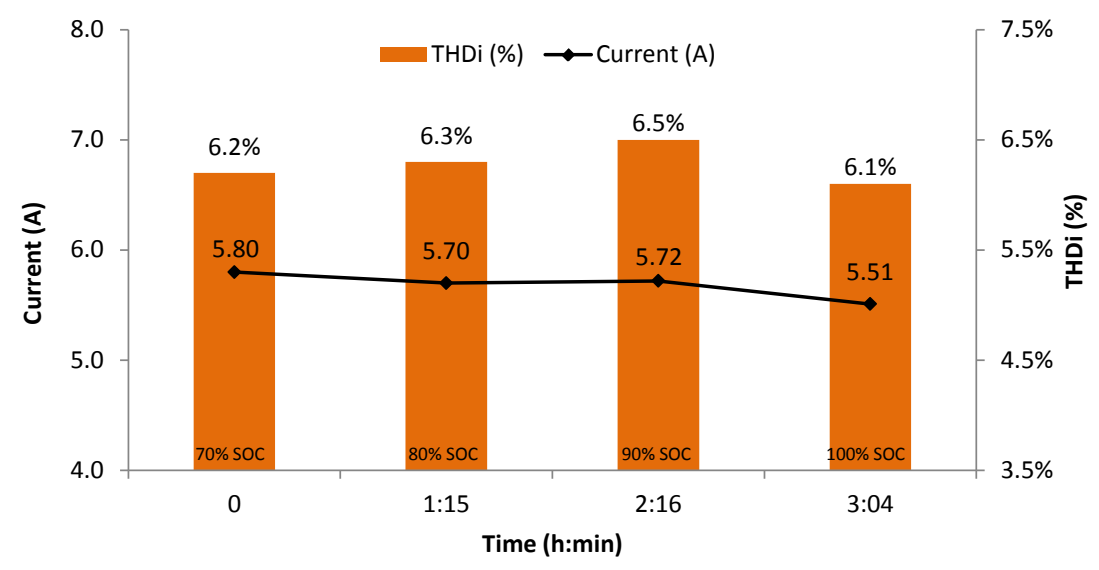

Figure 6. Current and THDi, on phase L2, during EV charging.

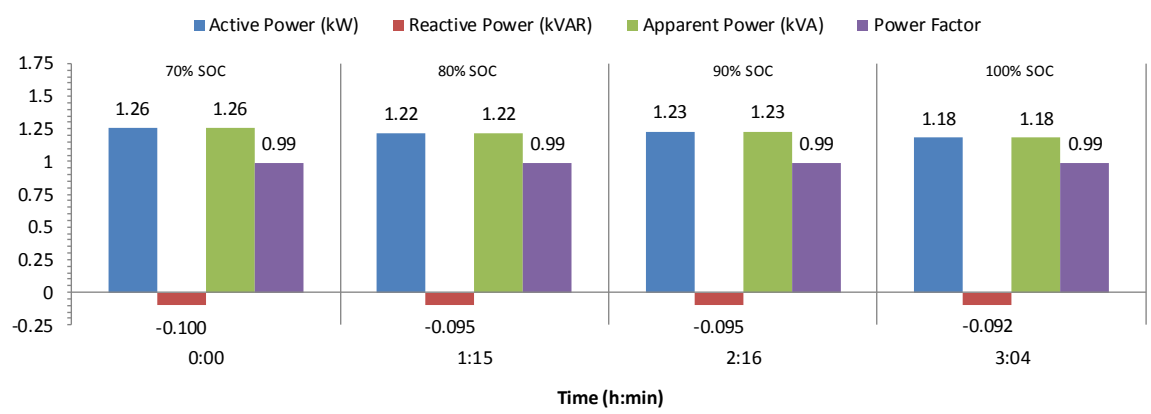

Figure 7. Powers $\mathrm{P}, \mathrm{Q}, \mathrm{S}$ and power factor, phase-to-phase, during EV charging.

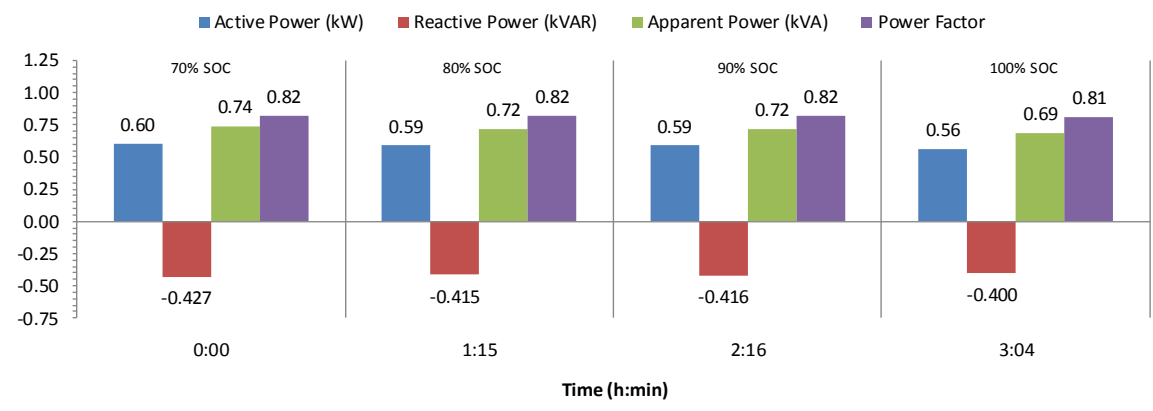

Figure 8. Powers P, Q, S and power factor, on phases L1, during EV charging. 


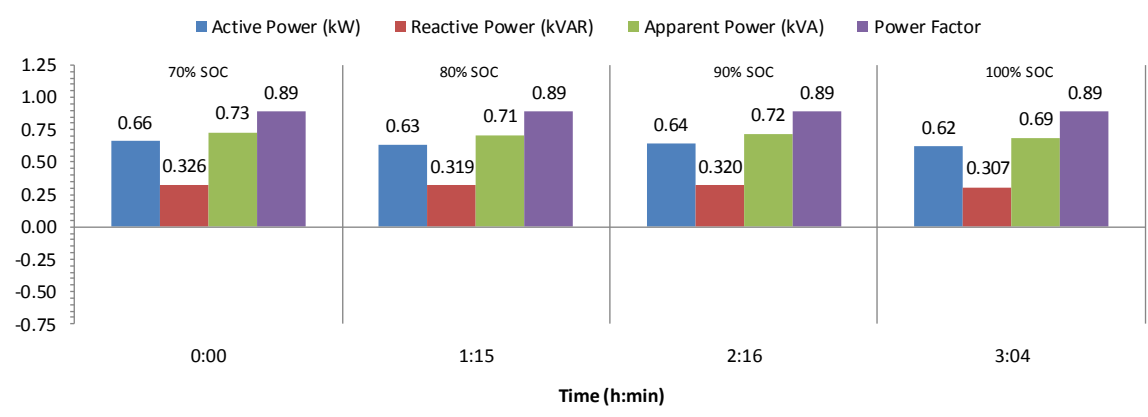

Figure 9. Powers $\mathrm{P}, \mathrm{Q}, \mathrm{S}$ and power factor, on phase L2, during EV charging.

per class [15] what in Brazil correspond to class B and A, respectively. The income of classes in Brazil is based on numbers of basic salary, where the monthly income of class B corresponds of more than 10 basic salaries and for class A more than 20 basic salaries [16]. Considering that the monthly basic salary in Brazil is $\$ 302$ (in 2017) [17] [18], the monthly income of class B is above $\$ 3200$ and for class $A$ is above $\$ 6400$. The class $A$ represents $2 \%$ of Brazilian families while the class B represents $12.6 \%$ [19]. Due to class B is composed of a significant share of EV owners, this class has been analyzed in this study. The effect of the EV charging has been analyzed considering a load curve of a typical residence belongs to class B. It has been used a typical daily load curve, obtained through measurements on distribution circuits [20]. It was used a typical workday load curve, with mensal consume of $300 \mathrm{kWh}$, what correspond $10 \mathrm{kWh}$ per day and maximum energy demand of $0.847 \mathrm{~kW}$. The curve profile can be observed in Figure 10.

When the analyzed EV is connected to home to recharge, it will change the behavior of the residential daily load curve. Its impact depends on the EV penetration time. To analyze the impact of the $\mathrm{EV}$ as a load in the residence of class $\mathrm{B}$, the data obtained by measurements has been included in two condition of recharge as described bellows:

- C1-Condition 1 of EV charging. After travelled $41 \mathrm{~km} /$ day, in the end of day the battery of $\mathrm{EV}$ is with $70 \%$ SOC. At seven p.m, the EV starts the recharge on a residence of class $B$.

- C2-Condition 2 of EV charging. After travelled $41 \mathrm{~km} /$ day, in the end of day the battery of EV is with 70\% SOC. At eleven p.m, the EV starts the recharge on a residence of class $\mathrm{B}$.

The proposal is to evaluate, further the electric parameters, how the period of the day to initiate the EV charging can impact on power system.

\subsection{Condition 1 of EV Charging}

Firstly, the EV will start the recharge at seven p.m., a common time to use the main devices at home. The new load curve is shown in Figure 11. The behavior on phase L1 and L2 are shown on Figure 12 and Figure 13, respectively.

With EV recharging in the residence, it shapes the load profile in a "sharp peak", as a consequence, the monthly power consumption increased to 416.55 


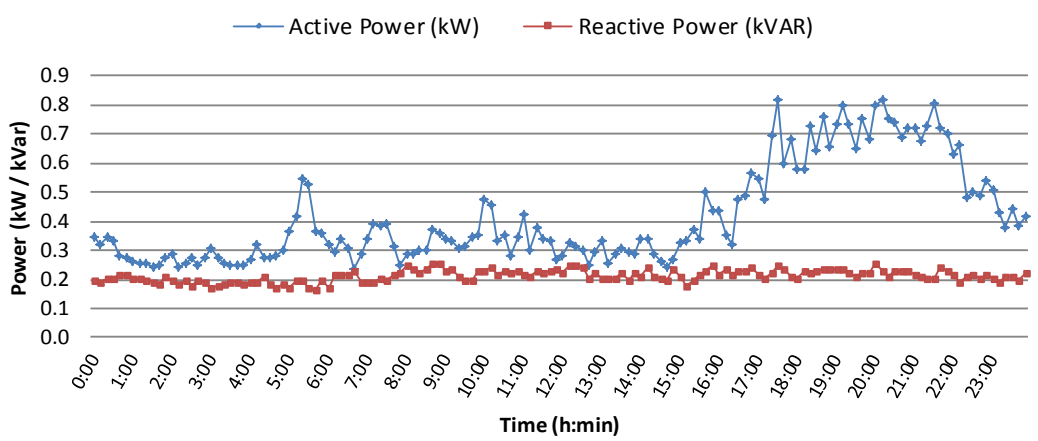

Figure 10. Residential daily load curve of class B-Workdays.

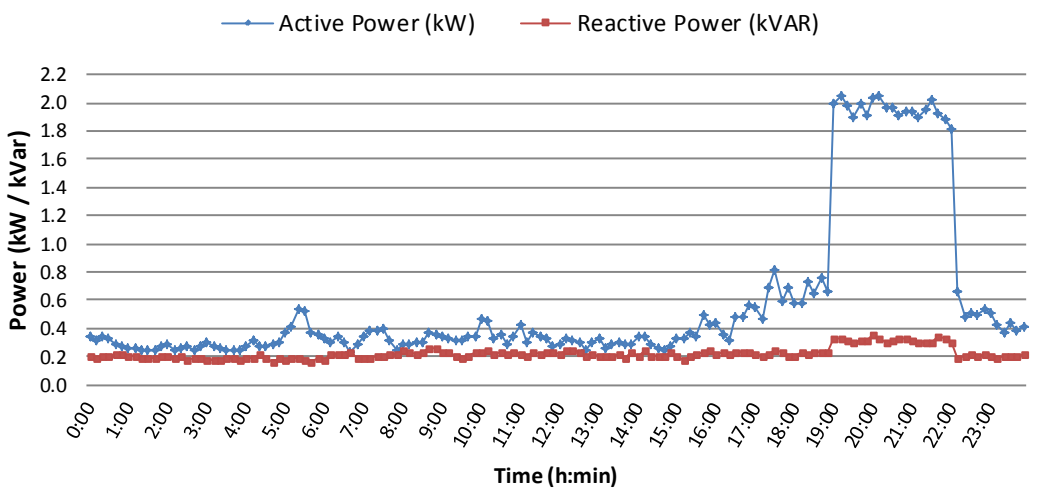

Figure 11. Residential daily load curve with EV charging at seven p.m.

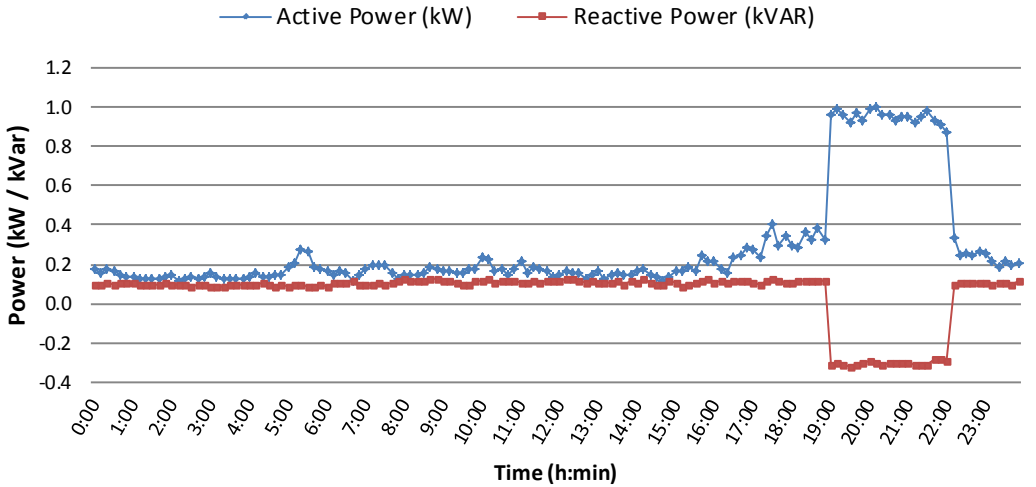

Figure 12. Energy demand on phase L1 during EV charging at seven p.m.

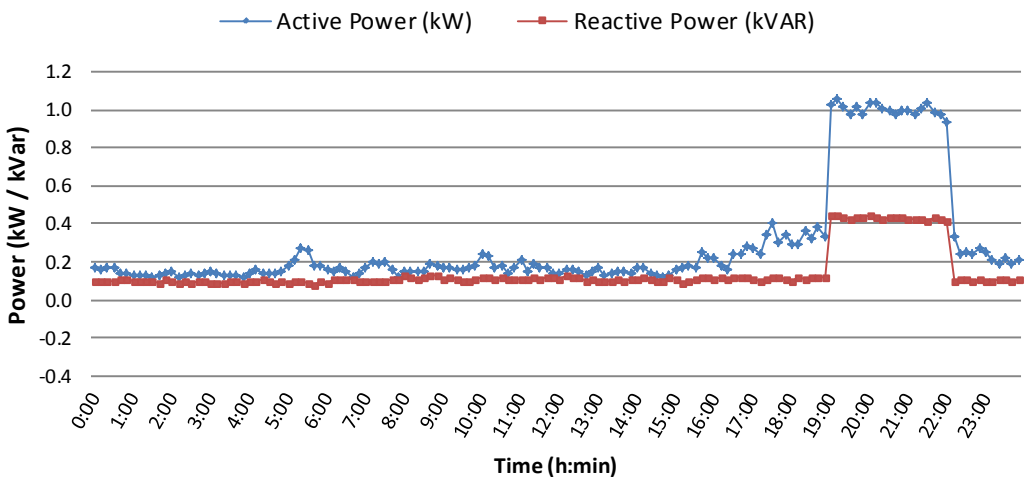

Figure 13. Energy demand on phase L2 during EV charging at seven p.m. 
$\mathrm{kWh}$ and the maximum power demand jumped to $2.052 \mathrm{~kW}$ (142\% bigger than the normal case value). As observed in Figure 10, the EV is a significant load and it causes a great modify on residential load curve behavior due to the EV energy demand. In Figure 10, the reactive power remained in low values. However, it is possible to observe high values of reactive power between the phases L1 and ground and L2 and ground, with inverse values to compensate the imbalance between the phases. When the recharge starts at seven p.m., the EV uses the energy simultaneously with the period of the day with higher consumption in the house. A group of houses is connected in transformers in the distribution net. Each transformer is designed to feed the consumers considering their typical load curves. If the residence load curve changes, the energy company has to relocate loads to avoid peak demand out of the limit. This kind of scenario (C1) is the worst one as the standard peak load (before EV introduction) occurs around $7 \mathrm{pm}$. Consequently it can cause overload on transformers. Whenever possible, it is important to relocate the consumption of main devices to periods out of the peak energy interval, to avoid overload on electrical system.

\subsection{Condition 2 of EV Charging}

The second analysis was done considering that the EV starts it charging at eleven p.m., out of the peak energy period. Figure 14 present the new load curve and the behavior on phase L1 and L2 to ground are shown on Figure 15 and Figure 16 , respectively.

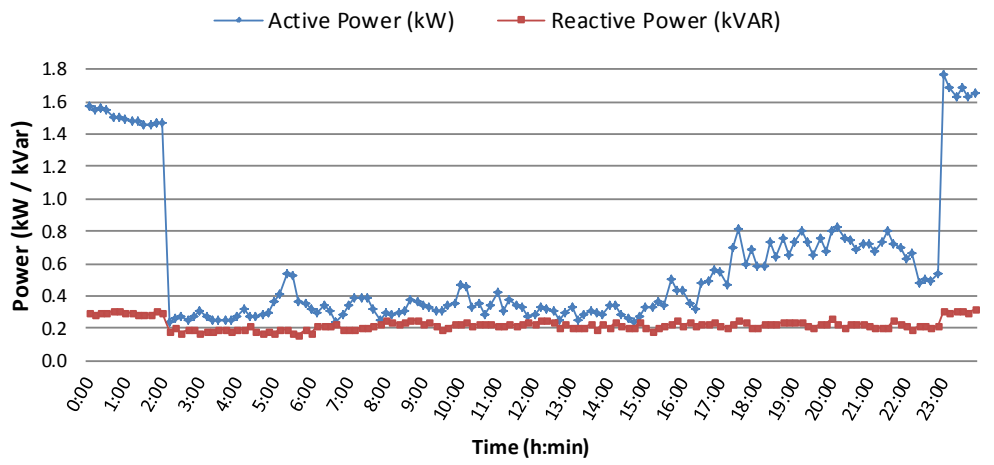

Figure 14. Residential daily load curve with EV charging at eleven p.m.

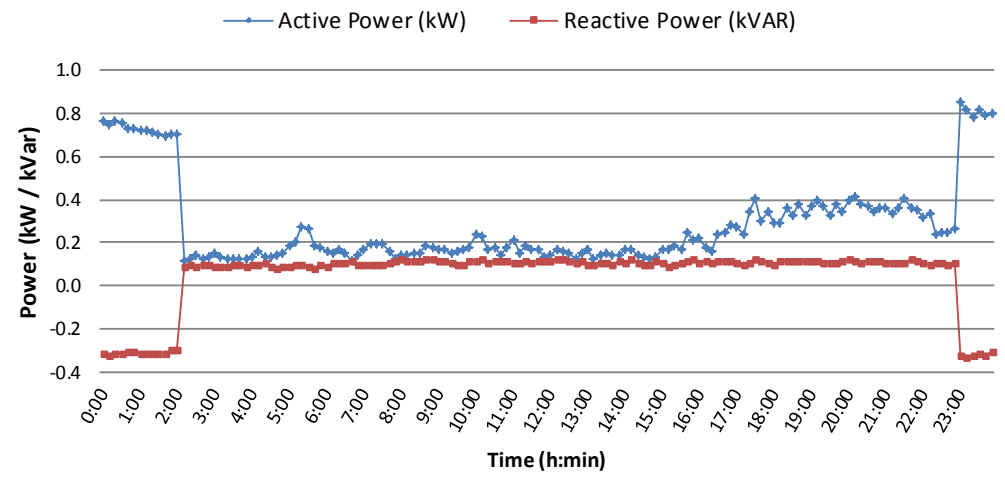

Figure 15. Energy demand on phase L1 during EV charging at eleven p.m. 


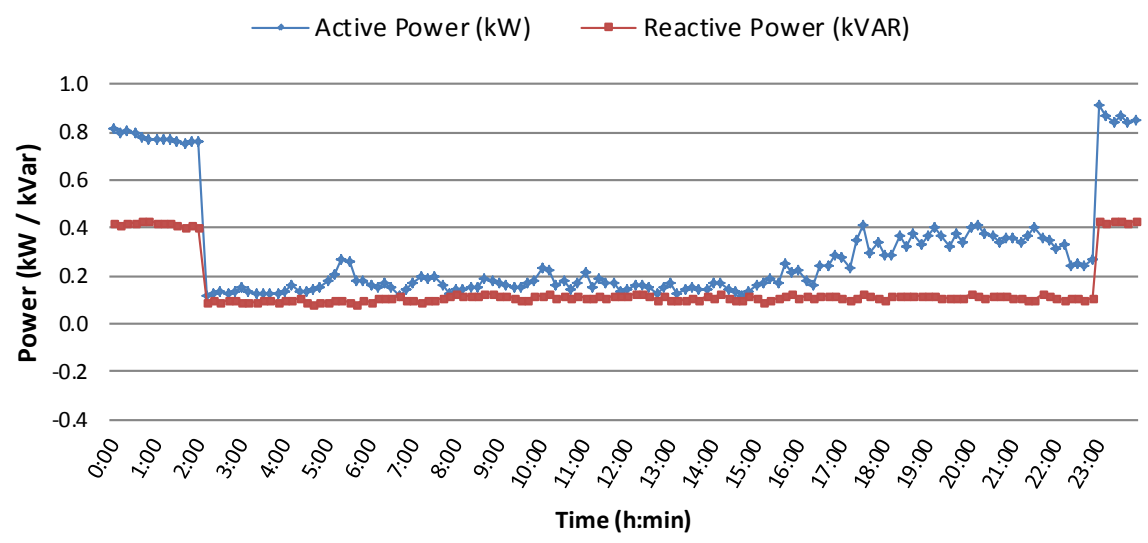

Figure 16. Energy demand on phase L1 during EV charging at eleven p.m.

In the residence, the monthly energy consumption increased to the same value found on $\mathrm{C} 1$ ( $416.55 \mathrm{kWh})$ as expected. Therefore, the maximum power demand increased to $1.764 \mathrm{~kW}$ (108\% bigger than the normal value) and comparing with scenario $\mathrm{C} 1$ it reduced by $14 \%$, from $2.052 \mathrm{~kW}$ to $1.764 \mathrm{~kW}$. When the recharge starts at eleven p.m., the EV uses the power energy in a period of day without or with less consumption of energy in the house. It can avoid overload on transformers and distribution lines during the power system peak time (around 7pm) but can cause another peak time for residential area after $11 \mathrm{pm}$. The results demonstrate how it is significant the time to start the recharge of an electric vehicle. It impacts definitely in increases of energy demand.

The reactive power between phases L1-L2 is shown in Figure 14 and it remains with low values. Analyzing the phases separately, it can be seen bigger values of reactive power with inverse values on phases L1 and L2 to ground. They are presented in Figure 15 and Figure 16, respectively.

\section{Conclusion}

In this paper, it was proposed to analyze the behavior of electric parameters during EV charging on power system. These parameters were analyzed together with the residential load curve of class B to analyze the impact caused by the recharge of EV on typical Brazilian residences. There is a concern about the inclusion of EV on electrical system which can cause overload on distribution lines and transformers. Moreover, it can affect the power quality of system. On results phase-to-phase (L1-L2), the evaluation of measurements shows low harmonic penetration and high power factor value. When the analysis is about each phase L1 and L2 to ground, each one has high reactive power. But due to the inverse values on phases L1 and L2, the final results attend quality power standards. To evaluate the impact on power system, the data measured were inserted on a residential load curve of class B in two scenarios of recharge, $\mathrm{C} 1$ and $\mathrm{C} 2$. In $\mathrm{C} 1$, the recharge of EV starts at 7 p.m. and in $\mathrm{C} 2$, the recharge starts at 11 p.m. The introduction of $\mathrm{EV}$ on $\mathrm{C} 1$ has caused a jump on maximum energy demand because the EV consumption was addicted in a period of the day where it occurs the higher consumption in the house. It can cause overload on transformers that 
supports other houses with the same consumption behavior. On C2, the monthly energy consumption increased to the same value observed in $\mathrm{C} 1$, because the consume of $\mathrm{EV}$ is the same, but the maximum energy demand was lower than in $\mathrm{C} 1$ because $\mathrm{C} 2$ occurred in a time when it does not have high consume of energy. Analyzing the graphics it is possible to understand how it is significant the time to start the recharge of EV. It impacts definitely in increases of energy demand on power system. Therefore, it is necessary to have specifics politics to stimulate the behavior of $\mathrm{EV}$ charging for off peak consumption periods.

\section{References}

[1] Udaeta, M.E.M., Chaud, C.C., Gimenes, A.L.V. and Galvao, L.C.R. (2015) Electric Vehicles Analysis inside Electric Mobility Looking for Energy Efficient and Sustainable Metropolis. Open Journal of Energy Efficiency, 4, 1-14. https://doi.org/10.4236/ojee.2015.41001

[2] Mohd, Z.C.W., Mohd, F.S., Afida, A., Sibiyanto, Azah, M., Abu, H., Saharuddin, S. Mohamed, A., Zahrul, F.H. and Ahmad, K.M. (2013) Harmonic Measurement and Analysis during Electric Vehicle Charging. Open Journal of Engineering, 5, 215 220.

[3] Lun, K.L., King, T.K., Hoi, Y.T, Hoi, C.T., Wah, C.L., Kim, F.T. and Loi, L.L. (2011) Advanced Metering Infrastructure for Electric Vehicle Charging. Smart Grid and Renewable Energy, 2, 312-323. https://doi.org/10.4236/sgre.2011.24036

[4] Cao, J. and Emadi, A. (2009) A New Battery/Ultra-Capacitor Hybrid Energy Storage System for Electric, Hybrid and Plug-In Hybrid Electric Vehicles. Illinois Institute of Technology, Chicago.

[5] Gao, Y. and Guo, Y. (2013) Optimal Planning of Charging Station for Phased Electric Vehicle. Energy and Power Engineering, 5, 1393-1397. https://doi.org/10.4236/epe.2013.54B264

[6] Rodriguez, D., Avila, C. and Mejia, W. (2013) Impact of Electric Vehicle on Power System Operation: Technical Overview. International Journal of Engineering Research \& Technology, 2, 2223-2230.

[7] CETESB (2013) Intensity Curves of Use by Type of Automobiles of Fleet's San Paulo City. Report of Environmental Secretariat, Sao Paulo.

[8] U.S. Department of Energy (2014) Fuel Properties Comparison. http://www.afdc.energy.gov/fuels/fuel_comparison_chart.pdf

[9] IEEE (2014) IEE Std. 519-2014: IEEE Recommended Practice and Requirements for Harmonic Control in Electric Power Systems. IEEE, New York.

[10] IEC. (2014) IEC Std. 61000-3-2: Limits for Harmonic Current Emissions (Equipment Input Current $\leq 16 \mathrm{~A}$ per Phase. IEC, Genève.

[11] ANEEL (2016) PRODIST Module 8-Quality Power. Revision 7.

[12] Lovato Electric. Digital Multimeter DMG200-DMG210. Instructions Manual.

[13] GE Energy Management (2012) Solutions for Electric Vehicles Charging. Products Catalog.

[14] ITS (2013) Who Is Buying Electric Cars in California? Exploring Household and Vehicle Fleet Characteristics of New Plug-In Vehicle Owners. University of California, Davis.

[15] Pew Research Center (2016) Are You in the American Middle Class? http://www.pewsocialtrends.org/2016/05/11/are-you-in-the-american-middle-class/ 
[16] FPA (2013) Social Classes in Brazil Today. FPA Discute, Wladimir Pomar, Foundation Perseu Abramo, 5-50.

[17] Brazil. Decreto No 8.618 de 29 de Dezembro de 2015. Brasilia.

[18] Banco Central do Brasil (2016) Exchange Rates of 12/02/2016. http://www4.bcb.gov.br/pec/taxas/ingl/ptaxnpesq.asp?id=quotations

[19] Gerbelli, L.G. (2016) Class A Has the Mayor Parcel of Income of the Country. O Estado de S. Paulo, Sao Paulo.

http://economia.estadao.com.br/noticias/geral,classe-a-tem-maior-fatia-da-renda-d o-pais, 10000007285

[20] Yamakawa, E.K. (2007) Fuzzy Logic System for Automatic Capacitor Banks Applied in Power Distribution Feeders. Ph.D. Dissertation, Federal University of Curitiba, Curitiba.

http://acervodigital.ufpr.br/bitstream/handle/1884/14076/Dissertacao\%20Final\%20 Eduardo.pdf?sequence $=1$

Submit or recommend next manuscript to SCIRP and we will provide best service for you:

Accepting pre-submission inquiries through Email, Facebook, LinkedIn, Twitter, etc. A wide selection of journals (inclusive of 9 subjects, more than 200 journals)

Providing 24-hour high-quality service

User-friendly online submission system

Fair and swift peer-review system

Efficient typesetting and proofreading procedure

Display of the result of downloads and visits, as well as the number of cited articles

Maximum dissemination of your research work

Submit your manuscript at: http://papersubmission.scirp.org/

Or contact jpee@scirp.org 